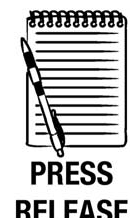

RELEASE

\title{
MUltiple Sclerosis and Extract of Cannabis: results of the MUSEC trial
}

\author{
John Peter Zajicek, ${ }^{1}$ Jeremy C Hobart, ${ }^{1}$ Anita Slade, ${ }^{1}$ David Barnes, ${ }^{2}$ \\ Paul G Mattison, ${ }^{3}$ on behalf of the MUSEC Research Group
}

${ }^{1}$ Clinical Neurology Research Group, Peninsula College of Medicine and Dentistry, University of Plymouth, Derriford, UK

${ }^{2}$ Department of Neurology, St George's Healthcare NHS Trust, London, UK

${ }^{3}$ Multiple Sclerosis Service, Ayrshire Central Hospital, Irvine, Ayrshire, UK

\section{Correspondence to}

Professor J P Zajicek, Peninsula College of Medicine and Dentistry, University of Plymouth, Clinical Neurology Research Group, TSP, ITTC Building 1, Derriford, PL6 8BX, UK; john.zajicek@nhs.net

See appendix for list of investigators of the MUSEC Research Group.

Received 9 February 2012 Revised 11 June 2012 Accepted 12 June 2012 Published Online First 12 July 2012

\begin{abstract}
Objective Multiple sclerosis (MS) is associated with chronic symptoms, including muscle stiffness, spasms, pain and insomnia. Here we report the results of the Multiple Sclerosis and Extract of Cannabis (MUSEC) study that aimed to substantiate the patient based findings of previous studies.
\end{abstract}

Patients and methods Patients with stable MS at 22 UK centres were randomised to oral cannabis extract (CE) $(N=144)$ or placebo $(N=135)$, stratified by centre, walking ability and use of antispastic medication. This double blind placebo controlled, phase III study had a screening period, a 2 week dose titration phase from $5 \mathrm{mg}$ to a maximum of $25 \mathrm{mg}$ of tetrahydrocannabinol daily and a 10 week maintenance phase. The primary outcome measure was a category rating scale (CRS) measuring patient reported change in muscle stiffness from baseline. Further CRSs assessed body pain, spasms and sleep quality. Three validated MS specific patient reported outcome measures assessed aspects of spasticity, physical and psychological impact, and walking ability.

Results The rate of relief from muscle stiffness after 12 weeks was almost twice as high with CE than with placebo (29.4\% vs $15.7 \%$; OR 2.26; $95 \%$ Cl 1.24 to 4.13 ; $p=0.004$, one sided). Similar results were found after 4 weeks and 8 weeks, and also for all further CRSs. Results from the MS scales supported these findings.

Conclusion The study met its primary objective to demonstrate the superiority of CE over placebo in the treatment of muscle stiffness in MS. This was supported by results for secondary efficacy variables. Adverse events in participants treated with CE were consistent with the known side effects of cannabinoids. No new safety concerns were observed.

Trial registration number NCT00552604.

\section{INTRODUCTION}

Of the many symptoms encountered in multiple sclerosis (MS), muscle stiffness as a result of increased pyramidal tone and spasms occurs in up to $90 \%$ of patients at some time. ${ }^{1}$ This often leads to considerable distress from pain, reduced mobility and interference with activities of daily living, including sleep quality.

Current symptomatic therapy often provides inadequate relief and may be limited by toxicity. As a consequence, people with MS have experimented with many alternative therapies to ease their physical problems, including cannabis. ${ }^{2}{ }^{3}$ It has been estimated that between $1 \%$ and $4 \%$ of the total UK MS population is using cannabis for symptom relief. ${ }^{4}$
Several phase III trials of cannabinoids in MS have been conducted in recent years, the largest of which was the Cannabinoids in Multiple Sclerosis (CAMS) study. ${ }^{5}$ This double blind, placebo controlled study evaluated the effect of cannabinoids on symptoms such as spasticity, pain and sleep quality. Although the analysis did not show significant benefit using the primary outcome measure, the Ashworth Scale, patients themselves rated cannabinoids as clearly helpful. In the 1 year blinded follow-up of the CAMS study, there was a small significant treatment effect on muscle spasticity seen in the Ashworth score, with spasticity, spasms, pain and energy significantly improved in patient subjective ratings. ${ }^{6}$ The limitations of the single item, semi-objective Ashworth Scale in measuring the highly complex phenomenon of spasticity are well known, and it is now not recommended for spasticity assessment. ${ }^{78}$ As well as difficulties with outcome measures, other problems encountered in evaluating the potential benefit of cannabinoids for MS symptoms have included high placebo response rates and potential unmasking of treatment group, either due to side effects or improved symptoms.

We therefore designed the present phase III clinical trial (MUltiple Sclerosis and Extract of Cannabis (MUSEC)) to investigate a standardised oral cannabis extract (CE) for the symptomatic relief of muscle stiffness and pain in adult patients with stable MS and ongoing troublesome muscle stiffness. We used an 11 point numerical rating of change scale as a more patient orientated measure of efficacy than the Ashworth Scale, as recommended by the European Medicines Agency. ${ }^{9}$ As well as being used in this and previous studies, ${ }^{5}$ this type of scale is also being used as the standard outcome in other studies for licensing purposes. ${ }^{10}$ Additionally, we used newer patient reported outcome measures in order to investigate which aspects of MS were most likely to benefit from CE use.

\section{METHODS}

\section{Participants}

Patients aged 18-64 years with a diagnosis of MS according to the McDonald criteria, ${ }^{11}$ who had had stable disease for the previous 6 months and troublesome and ongoing muscle stiffness for at least 3 months before enrolment (as shown by a current disability score of at least 4 on an 11 point category rating scale (CRS)), were enrolled.

All physiotherapy regimens or medications likely to affect spasticity were adjusted, where necessary, before study entry and not altered in the 30 days 
before study start. Patients with active sources of infection or taking immunomodulatory drugs that might affect spasticity (eg, $\beta$-interferon, but not azathioprine) were excluded. Other exclusion criteria included fixed tendon contractures, severe cognitive impairment, history of psychosis, major illness, pregnancy and cannabis use in the 30 days before study start.

The study was approved by the Scotland A Research Ethics Committee and is registered at http://www.clinicaltrials.gov (NCT00552604).

\section{Randomisation and masking}

Participants were evenly allocated to CE or placebo by means of an interactive voice response system. Computer generated permuted block randomisation was used, stratified by centre, ambulatory status (able to walk or not) and concurrent use of antispasticity medication (yes or no). Active treatment was an extract from Cannabis sativa L (extraction medium ethanol 96\%) in soft gelatine capsules, standardised on cannabidiol (range $0.8-1.8 \mathrm{mg}$ ) and containing $2.5 \mathrm{mg} \Delta^{9}$ - tetrahydrocannabinol (THC) as the main cannabinoid (Cannador; Society for Clinical Research, Berlin, Germany). Matched placebo capsules contained the same partial glyceride vehicle (Imwitor 742; Hüls AG, Marl, Germany). The study coordinating team, all investigators and participants were blinded to treatment allocation throughout.

\section{Study conduct}

The study consisted of a pretreatment screening period of 1-2 weeks, a 2 week dose titration phase and a 10 week maintenance phase. Total treatment duration was 12 weeks. Participants were assessed at 2, 4, 8 and 12 weeks after the start of treatment.

The starting dose was $2.5 \mathrm{mg} \Delta^{9} \mathrm{THC}$ (one capsule) twice daily. Subsequent doses were individually titrated upwards by $5 \mathrm{mg} \Delta^{9} \mathrm{THC} /$ day every 3 days for up to 12 days to optimise the ratio between therapeutic effect and side effects, and to achieve a maximum daily dose. The maximum allowable total daily dose was $25 \mathrm{mg} \Delta^{9} \mathrm{THC}$. Participants used diaries to record capsules taken daily.

In the event of intolerable side effects, the daily dose was reduced by one capsule until the side effect(s) resolved. After resolution, one rechallenge with a further dose escalation was required. If the side effect(s) returned, the dose was reduced again, with no further rechallenge allowed.

The primary outcome measure was an 11 point CRS to evaluate perceived change in muscle stiffness after 12 weeks of treatment compared with the premedication phase. At the final visit, participants answered the following question on a symptom questionnaire: "Compared with before the study started, my muscle stiffness over the last week has been..." providing a rating on an 11 point numerical CRS where $0=$ very much better, $5=$ no difference and $10=$ very much worse. Categories $0-3$ of the rating scale were classified as 'relief of muscle stiffness' - that is, as a clinically relevant response.

Secondary outcome measures included further equivalent CRSs measuring perceived relief from body pain, muscle spasms and sleep disturbance compared with pretreatment (at 4, 8 and 12 weeks). Absolute amount of muscle stiffness, body pain, muscle spasms and sleep disturbance (at screening, baseline and 4, 8 and 12 weeks) was also asked for by similar 11 point rating scales stating "Over the last week, the (symptom) I have had is ..." providing a rating in categories between 'no (symptom)' and 'extreme (symptom)'. Further patient reported secondary outcome measures included validated disease specific multi-item rating scales measuring aspects of spasticity in MS (MS Spasticity Scale (MSSS-88)), ${ }^{12}$ the physical and psychological impact of MS
(MS Impact Scale (MSIS-29)) ${ }^{13}$ and walking ability (MS Walking Scale (MSWS-12)) ${ }^{14}$ (at screening, baseline, 4 and 12 weeks).

Investigators evaluated severity of disability (Expanded Disability Status Scale (EDSS) $)^{15}$ and all safety parameters at screening and at week 12 . Safety was evaluated using laboratory parameters, vital signs and adverse events (AEs), in accordance with good clinical practice.

\section{Calculation of sample size}

In the CAMS study, $27 \%$ of placebo participants and $42 \%$ of $\mathrm{CE}$ participants showed relief from muscle stiffness, as defined in the present study. Assuming a two sided test of hypothesis with a power of $80 \%$, a $5 \%$ level of significance and an active treatment to placebo ratio of $1: 1$, about 170 evaluable participants per group would be required to detect a significant improvement in relief rate compared with placebo, according to the sample size approximation of Casagrande et al for Fisher's exact test. ${ }^{16}$ With an assumed dropout rate of $15 \%$, it was planned to enrol a total of 400 patients.

An unblinded adaptive interim analysis was planned by means of ADDPLAN software V.4 and performed at an $\alpha$ error level of $\alpha=0.0026$ after the first 200 patients had completed the study, applying the inverse normal procedure of Wassmer with stopping boundaries of O'Brien and Fleming. ${ }^{17-19}$ On the basis of this analysis, the Independent Data Monitoring Board recommended reducing participant numbers from 400 to 300 as this sample size was sufficient to maintain a conditional power of $95 \%$. The postinterim results confirmed the validity of this approach.

\section{Statistical analysis}

All decisions regarding primary outcome data were finalised by a blind data review panel before unblinding. SAS/STAT software (V.8.02) was used, based on a pre-agreed analysis plan. ${ }^{20}$ All primary and sensitivity analyses were carried out on the full analysis set (FAS) (ie, all patients enrolled), had at least screening/baseline measurements and had taken at least one dose of study medication. For the efficacy analysis, missing data were replaced by the last observation carried forward approach. In addition, as a sensitivity assessment of the primary efficacy parameter, worst case and multiple imputation substitutions were performed.

The primary analysis of efficacy compared the proportion of patients with relief from muscle stiffness $(0-3$ on the CRS) in the $\mathrm{CE}$ and placebo arms. A logistic regression model was used with fixed factors treatment (binary), ambulatory status at screening (binary), use of spasticity medication (binary) and geographical region (binary dummy coded). A one sided test for superiority of CE over placebo was performed with a prespecified $\alpha$ error level of $\alpha=0.024$ for the final analysis, incorporating a global error level of $\alpha=0.025$ combined from the interim and final analyses.

Secondary efficacy endpoints were analysed in the same way as the primary endpoint for numerical rate of change scales or non-parametrically for amount of symptoms in CRS and MS specific questionnaires. The MSSS-88 has eight sections measuring three spasticity related symptoms, effect of spasticity on three aspects of physical function and two aspects of psychosocial function. Analysis included the factors treatment, ambulatory status and antispasticity medication (all binary) using Lehmann's non-parametric aligned rank test.

The MSIS-29 has two scales measuring the self-reported physical impact (20 items) and psychological impact (nine items) of MS, each with five response options. The MSWS-12 is a self-rated measure of walking ability. This questionnaire was 
not administered in patients unable to walk and the analysis therefore included only the factor treatment (binary), evaluated using Wilcoxon's rank sum test.

The MSSS-88, MISIS-29 and MSWS-12 were also analysed using Rasch measurement methods. ${ }^{21-23}$ This modern psychometric analytic method has the advantage of deriving linear measurements from ordinal patient responses to items, and enabling legitimate analysis at the individual person level.

EDSS data at screening and after 12 weeks of treatment were listed and summarised.

The Cochran-Mantel-Haenszel- $\chi^{2}$ test was used to test for differences between the proportion of patients with AEs in the $\mathrm{CE}$ and placebo groups stratified for separate visits. Laboratory parameters were compared using Fisher's exact test.

All secondary and safety parameters where considered statistically significant with a (local) two sided error level of $\alpha=0.05$.

\section{RESULTS}

A total of 279 patients were randomised at 22 centres in the UK between June 2006 and September 2008 (figure 1).

Each centre randomised between one and 31 patients. Fifty-one patients failed the initial screening. One hundred and nine of the 144 patients randomised to CE (75.7\%) and 115 of the 135 patients randomised to placebo (85.2\%) completed the study. As one participant in each treatment group did not receive study medication, 277 randomised participants were included in the FAS. Demographic and baseline characteristics were similar in the two FAS treatment groups (tables 1 and 2). Although there were slightly more people with relapsing-remitting MS in the CE treated group, this was not significant and unlikely to have introduced bias by recovery from relapse, as all participants needed to be at least 6 months relapse free prior to study entry.

The proportion of patients with self-reported relief (defined as categories $0-3$ on the CRS) was $29.4 \%$ in the cannabis group
Figure 1 Disposition of patients and reasons for withdrawal. *Ten patients in the cannabis extract group and one patient in the placebo group were withdrawn from the study drug due to adverse events but completed the study. ITT, intention to treat; N, number of patients; $\mathrm{SAE}$, serious adverse event.

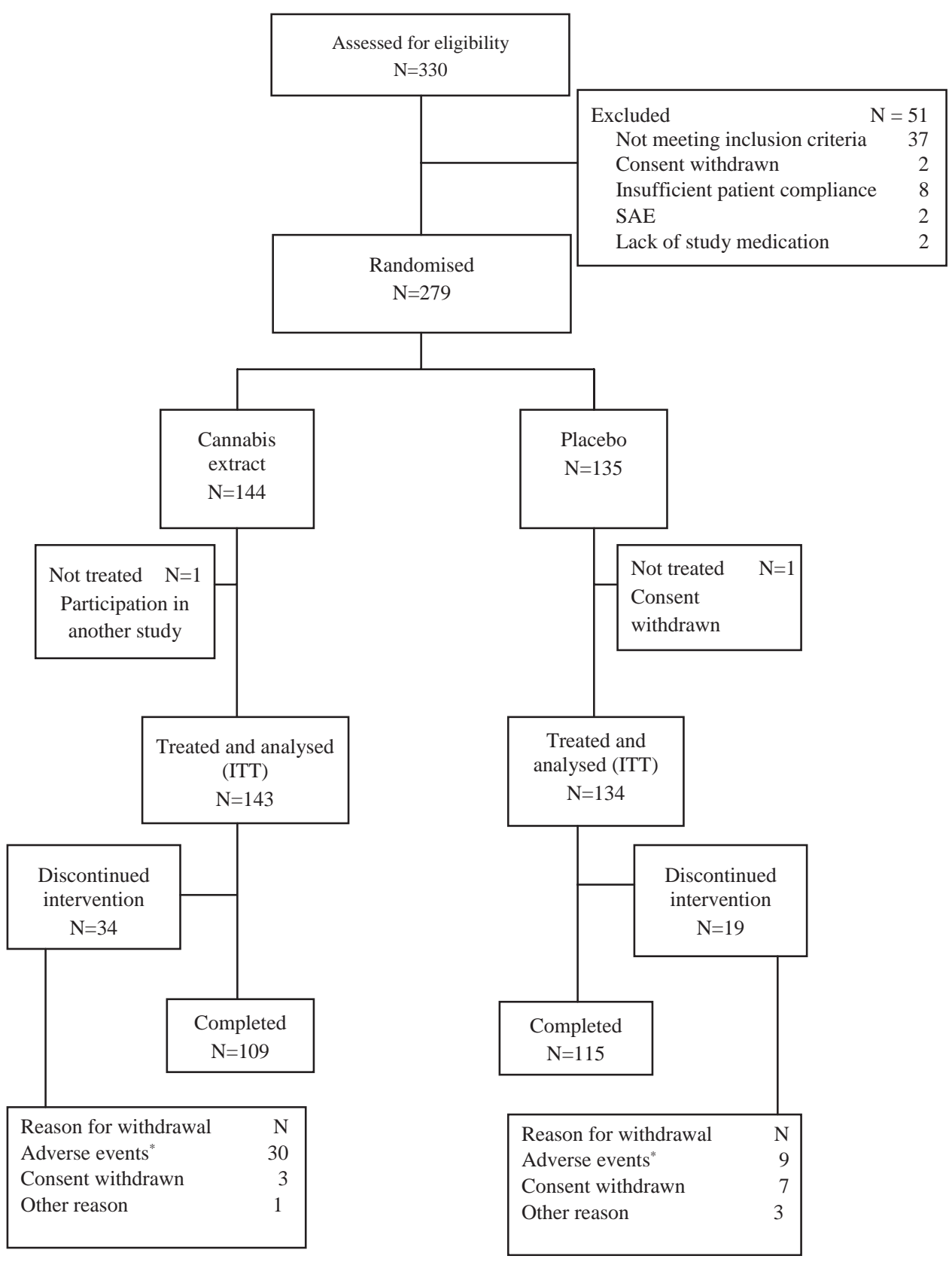


Table 1 Demographic characteristics

\begin{tabular}{|c|c|c|}
\hline Variable & $\begin{array}{l}\text { Cannabis } \\
\text { extract }(N=143)\end{array}$ & $\begin{array}{l}\text { Placebo } \\
(N=134)\end{array}$ \\
\hline \multicolumn{3}{|l|}{ Age (years) } \\
\hline Mean $\pm S D$ & $51.9 \pm 7.7$ & $52.0 \pm 7.9$ \\
\hline Median (range) & $53.0(32-64)$ & $54.0(28-64)$ \\
\hline \multicolumn{3}{|l|}{ Gender } \\
\hline Male (n (\%)) & $55(38.5)$ & $47(35.1)$ \\
\hline Female (n (\%)) & $88(61.5)$ & $87(64.9)$ \\
\hline \multicolumn{3}{|l|}{ Ethnic group } \\
\hline White (n (\%)) & 142 (99.3) & $133(99.3)$ \\
\hline Asian (n (\%)) & $1(0.7)$ & $1(0.7)$ \\
\hline Weight* $(\mathrm{kg})($ mean $\pm S D)$ & $75.31 \pm 16.52$ & $74.31(16.97)$ \\
\hline Height $(\mathrm{cm})($ mean $\pm S D)$ & $168.5(9.8)$ & $168.6(9.2)$ \\
\hline
\end{tabular}

and $15.7 \%$ in the placebo group (OR 2.26, 95\% CI 1.24 to 4.13 , $\mathrm{p}=0.004$, one sided) (table 3).

In a prespecified subgroup analysis (baseline status of the specific symptom (low vs high), geographic region, ambulatory status (walking vs non-walking) at screening and use of antispasticity or analgesic medication (yes or no)), more patients on CE experienced relief than on placebo, in all subgroups. The smallest difference was found between treatment groups in the non-walking subgroup (25.8\% CE group and $25.0 \%$ placebo group). The difference between treatment groups was most

Table 2 Baseline characteristics-full analysis set

\begin{tabular}{|c|c|c|}
\hline Parameter & $\begin{array}{l}\text { Cannabis extract } \\
(\mathrm{N}=143)\end{array}$ & $\begin{array}{l}\text { Placebo } \\
(N=134)\end{array}$ \\
\hline \multicolumn{3}{|l|}{ Time since first diagnosis of MS } \\
\hline Mean \pm SD (years) & $14.5 \pm 9.5$ & $15.1 \pm 8.4$ \\
\hline Median (range) (years) & $13.0(0-40)$ & $14.0(2-34)$ \\
\hline \multicolumn{3}{|l|}{ Form of MS } \\
\hline Relapsing-remitting (n (\%)) & $13(9.1)$ & $8(6.0)$ \\
\hline Primary progressive (n (\%)) & $34(23.8)$ & $32(23.9)$ \\
\hline Secondary progressive (n (\%)) & $96(67.1)$ & $94(70.1)$ \\
\hline \multicolumn{3}{|l|}{ Ambulatory status at screening } \\
\hline Non-walking (n (\%)) & $31(21.7)$ & $32(23.9)$ \\
\hline Walking (n (\%)) & $112(78.3)$ & $102(76.1)$ \\
\hline \multicolumn{3}{|l|}{ Baseline status of body pain } \\
\hline $\operatorname{Low}^{*}(\mathrm{n}(\%))$ & $49(34.3)$ & $54(40.3)$ \\
\hline Hight (n (\%)) & $94(65.7)$ & $80(59.7)$ \\
\hline \multicolumn{3}{|l|}{ Baseline status of muscle spasms } \\
\hline $\operatorname{Low}^{*}(\mathrm{n}(\%))$ & 27 (18.9) & $33(24.6)$ \\
\hline High† (n (\%)) & $116(81.1)$ & $101(75.4)$ \\
\hline \multicolumn{3}{|l|}{ Baseline status of quality of sleep } \\
\hline $\operatorname{Low}^{*}(\mathrm{n}(\%))$ & $47(32.9)$ & $54(40.3)$ \\
\hline High† (n (\%)) & $96(67.1)$ & $80(59.7)$ \\
\hline \multicolumn{3}{|l|}{ Use of spasticity medication } \\
\hline Yes (n (\%)) & $85(59.4)$ & $85(63.4)$ \\
\hline No (n (\%)) & $58(40.6)$ & $49(36.6)$ \\
\hline \multicolumn{3}{|l|}{ Use of analgesic medication } \\
\hline Yes (n (\%)) & $83(58.0)$ & $76(56.7)$ \\
\hline No (n (\%)) & $60(42.0)$ & $58(43.3)$ \\
\hline
\end{tabular}

pronounced in patients not using antispasticity medication (37.9\% CE group vs $16.3 \%$ placebo group).

Sensitivity analyses supported the robustness of the confirmatory (last observation carried forward) analysis (worst case analysis: $29.4 \%$ vs $20.1 \%$, OR $1.65,95 \%$ CI -1.59 to 20.04 , $\mathrm{p}=0.041$; multiple imputation: $30.8 \%$ vs $15.7 \%$, OR $2.36,95 \%$ CI 4.62 to $25.57, \mathrm{p}=0.003$ ).

Secondary efficacy variables were self-reported relief from muscle stiffness after 4 and 8 weeks of treatment, and relief from body pain, muscle spasms and sleep disturbance after 4,8 and 12 weeks of treatment. The rate of self-reported relief was consistently higher under CE than under placebo. At all visits, differences between treatment groups were statistically significant $(p<0.025$, one sided) for all variables (table 3$)$.

The only exception was the difference between the rate of relief from body pain after 12 weeks of treatment $(p=0.028)$. When this analysis was restricted to the subgroup of patients with high baseline pain scores, the treatment differences were greater because of lower placebo response rates (rates of relief after 4, 8 and 12 weeks for CE: $27.7 \%, 26.6 \%, 29.8 \%$; for placebo: $15.0 \%, 13.8 \%, 11.3 \%$ ) and the result was statistically significant, even at week $12(\mathrm{p}=0.001)$.

The OR for relief from muscle spasms increased over time due to an increase in the rate of relief from $\mathrm{CE}$ and because of an extremely low responder rate in the placebo group at week 12 . Response rates for improvement in quality of sleep were most pronounced for all CRS efficacy parameters, especially in the CE group, and ORs after 4 weeks and 8 weeks were the highest observed during the study.

In parallel with assessing the degree of relief from each symptom, participants determined the absolute level of MS symptoms they had had over the previous week. Baseline values were similar in the treatment groups. Ratings improved during the treatment phase from week 4 to week 8 and week 12, and mean symptom values were always lower in the CE group (table 4). With regard to change from baseline, differences between ratings after 12 weeks of treatment were statistically significantly in favour of CE for amount of muscle stiffness and amount of body pain (table 5).

Baseline values for MSSS-88, MSIS-29 and MSWS-12 were similar in the treatment groups. Ratings improved during treatment in both groups. Mean ratings were always in favour of the CE group, except for the MSSS-88 section 'effect of spasticity on daily activities' (table 5).

Differences between ratings after 12 weeks of treatment were statistically significant in favour of CE for sections of the MSSS88 measuring muscle stiffness, muscle spasms and effect of spasticity on body movements, and the MSWS-12.

The mean and median EDSS scores were similar in the treatment groups at screening and after 12 weeks of treatment.

At the end of the titration period, approximately $87 \%$ of participants in the placebo group were taking the maximum daily 'dose' of $25.0 \mathrm{mg}$. In contrast, only $47 \%$ of participants in the CE group had up titrated to a maximum daily dose of $25.0 \mathrm{mg}$. Of the CE patients who did not achieve the maximum daily dose, most were taking daily doses of 10.0 or $15.0 \mathrm{mg}$. Sixteen participants (11.2\%) in the CE group discontinued study medication during titration, compared with four in the placebo group (3.0\%)

At the end of the study, only $24.5 \%$ of CE participants were taking the $25.0 \mathrm{mg}$ dose, compared with $69.4 \%$ of placebo participants (table 6).

In total, 34 patients in the CE group (23.8\%) and 20 in the placebo group (14.9\%) discontinued study medication before the 
Table 3 Response rates in categorical rating scales for relief from symptoms at weeks 4, 8 and 12-frequency table per visit

\begin{tabular}{|c|c|c|c|c|c|c|}
\hline \multirow[b]{2}{*}{ Symptom $†$} & \multicolumn{2}{|l|}{ Week 4} & \multicolumn{2}{|l|}{ Week 8} & \multicolumn{2}{|l|}{ Week 12} \\
\hline & $\begin{array}{l}\text { Cannabis extract }(\mathrm{N}=143) \\
\mathrm{n}(\%)\end{array}$ & $\begin{array}{l}\text { Placebo }(\mathrm{N}=134) \\
\mathrm{n}(\%)\end{array}$ & $\begin{array}{l}\text { Cannabis extract }(\mathrm{N}=143) \\
\mathrm{n}(\%)\end{array}$ & $\begin{array}{l}\text { Placebo }(\mathrm{N}=134) \\
\mathrm{n}(\%)\end{array}$ & $\begin{array}{l}\text { Cannabis extract ( } \mathrm{N}=143) \\
\mathrm{n}(\%)\end{array}$ & $\begin{array}{l}\text { Placebo }(\mathrm{N}=134) \\
\mathrm{n}(\%)\end{array}$ \\
\hline Muscle stiffness & $44(30.8)$ & $20\left(14.9^{* *}\right)$ & $41(28.7)$ & $22\left(16.4^{* * *}\right)$ & $42(29.4)$ & $21\left(15.7^{* * *}\right)$ \\
\hline Body pain & $40(28.0)$ & $23\left(17.2^{* *}\right)$ & $43(30.1)$ & $26\left(19.4^{* * *}\right)$ & $40(28.0)$ & $25(18.7)$ \\
\hline Muscle spasms & $40(28.0)$ & $26\left(19.4^{*}\right)$ & $42(29.4)$ & $29\left(21.6^{*}\right)$ & $44(30.8)$ & $18\left(13.4^{* * *}\right)$ \\
\hline Sleep quality & $60(42.0)$ & $25\left(18.7^{* * *}\right)$ & $51(35.7)$ & $23\left(17.2^{* * *}\right)$ & $48(33.6)$ & $26\left(19.4^{* *}\right)$ \\
\hline
\end{tabular}

Difference between cannabis extract and placebo: ${ }^{*} \mathrm{p}<0.025,{ }^{* *} \mathrm{p}<0.005$ or ${ }^{* * *} \mathrm{p}<0.0025$, respectively (one sided logistic regression with ambulatory status, spasticity medication and region as fixed factors)

†Assessed by an 11 point numerical Likert scale $(0=$ very much better, .., $10=$ very much worse than symptoms prior to start of study); categories $0-3$ are defined as relief- that is, as clinically relevant response.

$\%$, percentage based on $\mathrm{N}$; $\mathrm{n}$, number of patients in specified category; $\mathrm{N}$, number of patients in specified treatment group.

end of the study, including the 20 patients who discontinued during titration.

Participants in the placebo group showed greater compliance (median index 98\%) with study treatment than those in the CE group (83\%).

There were no deaths during the study. Serious AEs (SAES) were reported for seven participants in the CE group (4.9\%) and for three participants in the placebo group (2.2\%). Urinary tract infection was reported as an SAE for three patients in the CE group $(2.1 \%)$. None of the other SAEs were reported for more than one participant.

Altogether, 233 of 277 participants (84.1\%) in the FAS experienced at least one treatment emergent $\mathrm{AE}$. The proportion of patients with AEs was higher in the CE group than in the placebo group (93.0\% vs $74.6 \%)$. Thirty patients in the CE group (21.0\%) and nine in the placebo group $(6.7 \%)$ were withdrawn from the study or discontinued study medication due to AEs. Despite this, more than $95 \%$ of AEs in each treatment group were mild or moderate, and the majority subsided after the end of study/treatment (table 7).
In the $\mathrm{CE}$ group, rates of $\mathrm{AEs}$ were highest during titration $(75.5 \%)$ and decreased continuously over the course of the study (table 8). AEs classed as nervous system disorders were most common $(71.3 \%)$, followed by gastrointestinal disorders (41.3\%). AEs that occurred at clearly higher rates in the $\mathrm{CE}$ group than in the placebo group (difference $>3 \%$ ) were dizziness, disturbance in attention, balance disorder, somnolence, dry mouth, nausea, diarrhoea, fatigue, asthenia, feeling abnormal, urinary tract infection, disorientation, confusional state and fall. Pain in extremities occurred at a higher rate in the placebo group than in the CE group. No relevant changes were seen for haematology, blood chemistry, urinalysis variables or vital signs.

\section{DISCUSSION}

Treatment with standardised oral extract of Cannabis sativa relieved muscle stiffness. The proportion of participants experiencing relief was almost twice as large in the CE group as in the placebo group $(29.4 \%$ vs $15.7 \%)$, which confirmed the superiority of $\mathrm{CE}$ over placebo in the treatment of muscle

Table 4 Category rating scales for amount of symptoms at weeks 4, 8 and 12

\begin{tabular}{|c|c|c|c|c|c|c|}
\hline \multirow[b]{2}{*}{ Questionnaire } & \multicolumn{2}{|l|}{ Week 4} & \multicolumn{2}{|l|}{ Week 8} & \multicolumn{2}{|l|}{ Week 12} \\
\hline & $\begin{array}{l}\text { Cannabis extract } \\
\bar{x} \pm S D\end{array}$ & $\begin{array}{l}\text { Placebo } \\
\overline{\mathbf{x}} \pm \text { SD }\end{array}$ & $\begin{array}{l}\text { Cannabis extract } \\
\overline{\mathbf{x}} \pm S D\end{array}$ & $\begin{array}{l}\text { Placebo } \\
\overline{\mathbf{x}} \pm \text { SD }\end{array}$ & $\begin{array}{l}\text { Cannabis extract } \\
\bar{x} \pm S D\end{array}$ & $\begin{array}{l}\text { Placebo } \\
\overline{\mathbf{x}} \pm \text { SD }\end{array}$ \\
\hline \multicolumn{7}{|l|}{$\mathrm{CRS}^{*}$} \\
\hline Muscle stiffness & $5.3 \pm 2.2$ & $6.1 \pm 2.3$ & $5.3 \pm 2.3$ & $6.2 \pm 2.6$ & $5.4 \pm 2.6$ & $6.4 \pm 2.6$ \\
\hline Body pain & $3.9 \pm 2.6$ & $4.5 \pm 3.0$ & $4.1 \pm 2.8$ & $4.6 \pm 3.2$ & $4.1 \pm 2.9$ & $4.7 \pm 3.0$ \\
\hline Muscle spasms & $4.5 \pm 2.6$ & $6.1 \pm 2.7$ & $4.6 \pm 2.5$ & $5.1 \pm 2.8$ & $4.7 \pm 2.7$ & $5.4 \pm 2.8$ \\
\hline Sleep quality & $3.6 \pm 2.6$ & $4.5 \pm 3.0$ & $3.8 \pm 2.7$ & $4.3 \pm 2.9$ & $3.8 \pm 2.9$ & $4.3 \pm 3.0$ \\
\hline \multicolumn{7}{|l|}{ MSSS-88† } \\
\hline Muscle stiffness & $30.3 \pm 8.3$ & $32.9 \pm 9.0$ & - & - & $31.8 \pm 9.6$ & $34.2 \pm 9.2$ \\
\hline Pain/discomfort & $21.0 \pm 7.0$ & $21.7 \pm 7.5$ & - & - & $21.7 \pm 7.6$ & $22.5 \pm 7.6$ \\
\hline Muscle spasms & $27.9 \pm 10.2$ & $28.8 \pm 11.1$ & - & - & $29.1 \pm 11.0$ & $30.5 \pm 12.1$ \\
\hline Daily activities & $30.1 \pm 9.3$ & $31.0 \pm 9.1$ & - & - & $31.4 \pm 10.1$ & $31.4 \pm 9.4$ \\
\hline Ability to walk & $31.2 \pm 8.4$ & $33.3 \pm 6.5$ & - & - & $31.6 \pm 7.9$ & $34.2 \pm 6.7$ \\
\hline Body movement & $29.3 \pm 9.2$ & $30.1 \pm 8.8$ & - & - & $30.0 \pm 10.0$ & $31.2 \pm 9.0$ \\
\hline Feelings & $29.4 \pm 12.0$ & $29.6 \pm 11.9$ & - & - & $30.9 \pm 11.9$ & $30.7 \pm 12.2$ \\
\hline Social functioning & $17.0 \pm 7.41$ & $17.4 \pm 6.8$ & - & - & $18.1 \pm 7.6$ & $17.6 \pm 7.2$ \\
\hline \multicolumn{7}{|l|}{ MSIS-29† } \\
\hline Physical impact & $58.1 \pm 24.1$ & $59.8 \pm 22.7$ & - & - & $58.6 \pm 25.7$ & $62.4 \pm 22.7$ \\
\hline Psychological impact & $38.7 \pm 25.7$ & $38.5 \pm 26.6$ & - & - & $42.0 \pm 27.5$ & $40.4 \pm 24.4$ \\
\hline \multicolumn{7}{|l|}{ MSWS-12‡ } \\
\hline Total score & $81.9 \pm 22.6$ & $87.6 \pm 15.5$ & - & - & $78.7 \pm 26.2$ & $89.6 \pm 14.6$ \\
\hline
\end{tabular}

*Assessed by an 11 point numerical Likert scale $(0=$ no symptom expression, ..., $10=$ extreme symptom expression).

†Possible answers: 1, not at all bothered/limited; 2, a little bothered/limited; 3, moderately bothered/limited; 4, extremely bothered/limited.

$\neq$ Possible answers: 1 , not at all; 2 , a little; 3 , moderately; 4, quite a bit; 5 , extremely.

CRS, category rating scale; MSIS-29, Multiple Sclerosis Impact Scale; MSSS-88, Multiple Sclerosis Spasticity Scale; MSWS-12, Multiple Sclerosis Walking Scale; N, number of patients in specified group; $\bar{x}$, mean symptom score. 
Table 5 Change from baseline in category rating scales for amount of symptoms and multiple sclerosis specific questionnaires

\begin{tabular}{|c|c|c|c|}
\hline \multicolumn{2}{|l|}{ Variable } & \multirow{2}{*}{$\begin{array}{l}\text { Cannabis extract }(\mathrm{N}=143) \\
\text { Mean } \pm S D\end{array}$} & \multirow{2}{*}{$\begin{array}{l}\text { Placebo ( } N=134 \text { ) } \\
\text { Mean } \pm \text { SD }\end{array}$} \\
\hline Questionnaire & Section & & \\
\hline \multirow[t]{4}{*}{ CRS $^{*}$} & Muscle stiffness & $-1.8 \pm 2.6$ & $-0.7 \pm 2.4 \ddagger$ \\
\hline & Body pain & $-1.2 \pm 2.6$ & $-0.3 \pm 2.4 \ddagger$ \\
\hline & Muscle spasms & $-1.5 \pm 2.7$ & $-0.7 \pm 2.4$ \\
\hline & Quality of sleep & $-1.4 \pm 3.1$ & $-0.9 \pm 2.6$ \\
\hline \multirow[t]{8}{*}{ MSSS-88§ } & Muscle stiffness & $-5.0 \pm 8.5$ & $-1.3 \pm 7.9 \neq$ \\
\hline & Pain and discomfort & $-3.0 \pm 6.4$ & $-1.6 \pm 6.2$ \\
\hline & Muscle spasms & $-5.2 \pm 9.9$ & $-2.1 \pm 9.2 \ddagger$ \\
\hline & Effect of spasticity on activities of daily living & $-1.3 \pm 8.0$ & $-1.6 \pm 8.2$ \\
\hline & Effect of spasticity on ability to walk & $-3.0 \pm 5.7$ & $-1.4 \pm 4.2$ \\
\hline & Effect of spasticity on body movement & $-3.9 \pm 7.7$ & $-1.8 \pm 7.9 \ddagger$ \\
\hline & Effect of spasticity on feelings & $-2.1 \pm 8.9$ & $-1.8 \pm 9.1$ \\
\hline & Effect of spasticity on social functioning & $-1.2 \pm 6.2$ & $-1.0 \pm 5.6$ \\
\hline \multirow[t]{2}{*}{ MSIS-29§ } & Physical impact & $-10.1 \pm 23.2$ & $-4.2 \pm 18.5$ \\
\hline & Psychological impact & $-6.3 \pm 23.7$ & $-3.8 \pm 22.8$ \\
\hline MSWS-12ף & Total score & $-9.0 \pm 17.6$ & $-1.7 \pm 12.4 \ddagger$ \\
\hline
\end{tabular}

Scores were transformed to a 0-100 scale using the formula $100 \times$ (observed score-minimum score)/(maximum score-minimum score).

${ }^{*}$ Assessed by an 11 point numerical Likert scale $(0=$ no symptom expression, ..., $10=$ extreme symptom expression).

$\neq$ Difference between cannabis extract and placebo: $p<0.025$ (one sided) (Lehmann's aligned rank test; factors for muscle stiffness and the MSSS-88-treatment, ambulatory status, spasticity medication; factors for body pain - treatment, analgesic medication, CRS baseline status; factors for muscle spasms and quality of sleep-treatment, spasticity medication, CRS baseline status; factors for MSIS-29 - treatment, ambulatory status; factor for MSWS-12-treatment).

§Possible answers: 1, not at all bothered/limited; 2, a little bothered/limited; 3, moderately bothered/limited; 4, extremely bothered/limited.

Possible answers: 1, not at all; 2, a little; 3, moderately; 4, quite a bit; 5, extremely.

CRS, category rating scale; MSIS-29, Multiple Sclerosis Impact Scale; MSSS-88, Multiple Sclerosis Spasticity Scale; MSWS-12, Multiple Sclerosis Walking Scale; N, number of patients in specified treatment group; mean, mean change from baseline.

stiffness. Sensitivity analyses using a worst case approach and multiple imputation of missing data corroborated the robustness of the results. Similar results were found in rates of relief from body pain, spasms and for sleep quality. It should be noted that a treatment effect after 12 weeks similar to the final analysis result had already been observed at the interim analysis. Based on the interim analysis of the FAS, it was possible to reduce the sample size, mainly for ethics reasons, while nevertheless maintaining a high conditional power for the remaining study.

Although rates of relief as defined in the present study were lower than expected based on the results from the CAMS study

Table 6 Extent of exposure to study medication - safety set

\begin{tabular}{|c|c|c|c|c|}
\hline \multirow[b]{2}{*}{ Daily dose (mg) } & \multicolumn{2}{|c|}{$\begin{array}{l}\text { Cannabis extract } \\
(\mathrm{N}=143)\end{array}$} & \multicolumn{2}{|l|}{$\begin{array}{l}\text { Placebo } \\
(N=134)\end{array}$} \\
\hline & $\begin{array}{l}\text { End of } \\
\text { titration } \\
\text { period } \\
\mathrm{n}(\%)\end{array}$ & $\begin{array}{l}\text { End of } \\
\text { study } \\
\text { period } \\
\mathrm{n}(\%)\end{array}$ & $\begin{array}{l}\text { End of } \\
\text { titration } \\
\text { period } \\
\text { n }(\%)\end{array}$ & $\begin{array}{l}\text { End of } \\
\text { study } \\
\text { period } \\
\mathrm{n}(\%)\end{array}$ \\
\hline 2.5 & $2(1.4)$ & $4(2.8)$ & $0(0.0)$ & $0(0.0)$ \\
\hline 5.0 & $5(3.5)$ & $6(4.2)$ & $0(0.0)$ & $0(0.0)$ \\
\hline 7.5 & $2(1.4)$ & $5(3.5)$ & $0(0.0)$ & $0(0.0)$ \\
\hline 10.0 & $15(10.5)$ & $13(9.1)$ & $2(1.5)$ & $3(2.2)$ \\
\hline 12.5 & $4(2.8)$ & $7(4.9)$ & $2(1.5)$ & $2(1.5)$ \\
\hline 15.0 & $16(11.2)$ & $13(9.1)$ & $6(4.5)$ & $7(5.2)$ \\
\hline 17.5 & $4(2.8)$ & $3(2.1)$ & $0(0.0)$ & $0(0.0)$ \\
\hline 20.0 & $6(4.2)$ & $8(5.6)$ & $3(2.2)$ & $8(6.0)$ \\
\hline 22.5 & $4(2.8)$ & $4(2.8)$ & $0(0.0)$ & $1(0.7)$ \\
\hline 25.0 & 67 (46.9) & $35(24.5)$ & 117 (87.3) & $93(69.4)$ \\
\hline Not applicable* & 16 (11.2) & $43(30.1)$ & $4(3.0)$ & $20(14.9)$ \\
\hline Missing & $2(1.4)$ & $2(1.4)$ & $0(0.0)$ & $0(0.0)$ \\
\hline
\end{tabular}

*Not applicable because patients discontinued taking study medication. $\%$, percentage (based on $N$ ); n, number of patients with data available; $N$, number of patients in specified treatment group. (overall rate of relief $34.5 \%$ in CAMS, $22.6 \%$ in MUSEC), the overall rate of relief from $\mathrm{CE}$ and placebo differed by $15 \%$ in both studies. As the most important secondary efficacy parameter, the rate of relief from body pain was also consistently higher in the CE group than in the placebo group.

Rating scales are increasingly being used as primary and secondary outcome measures in clinical studies in neurology. ${ }^{22}$ Evidence supports the use of a balanced 7 and 11 point numerical scale with written descriptors at the ends and in the middle of the scale, as used in the MUSEC study. Such instruments have the advantages of clinical relevance, adequate reproducibility and sensitivity to change, and are intuitively easy to understand by the patient and the person administering them. It must, however, be taken into account that a patient's condition at the time of asking might influence the rating change scorethat is, greater positive changes may be seen in patients with lower symptom severity scores, and vice versa.

Analysis of the MSSS-88, MSIS-29 and MSWS-12 data supported the outcome of the primary endpoint. For the MSSS88 sections with relatively high baseline values (ie, muscle stiffness, muscle spasms and effect of spasticity on body movements) and for the MSWS-12, the differences between ratings after 12 weeks of treatment compared with baseline were statistically significantly in favour of CE. A post hoc Rasch analysis has also been performed in order to support the main findings of this study, and will be presented elsewhere. Rasch analysis offers advantages over more traditional methods of analysing rating scale data that are clinically meaningful for neurology research. ${ }^{23} 24$

As would be expected, dose escalation resulted in a higher percentage of participants taking the maximum daily dose of $25.0 \mathrm{mg}$ in the placebo group than in the CE group. A relatively high proportion of participants in each treatment group had reduced their daily dose by the end of the study (placebo $17.9 \%$, CE $22.4 \%$ ). However, the proportion of CE patients still on the maximum daily dose at the end of the study was similar to the 
Table 7 Maximum frequency*, intensity and outcome of adverse events-safety set

\begin{tabular}{lcc}
\hline Category & $\begin{array}{c}\text { Cannabis extract } \\
\text { (N=143) } \\
\mathbf{n}(\%)\end{array}$ & $\begin{array}{l}\text { Placebo } \\
(\mathbf{N}=134) \\
\mathbf{n}(\%)\end{array}$ \\
\hline Frequency $\dagger$ & & \\
Dizziness & $89(46.2)$ & $10(6.7)$ \\
Urinary tract infection & $34(15.4)$ & $19(11.9)$ \\
Dry mouth & $34(23.1)$ & $10(7.5)$ \\
Headache & $22(11.2)$ & $20(11.9)$ \\
Asthenia & $25(13.3)$ & $11(8.2)$ \\
Fatigue & $25(14.0)$ & $9(6.0)$ \\
Intensity $\neq$ & & $177(61.2)$ \\
Mild & $347(55.3)$ & $102(35.3)$ \\
Moderate & $252(40.1)$ & $10(3.5)$ \\
Severe & $28(4.5)$ & $0(0.0)$ \\
Missing & $1(0.2)$ & $181(62.6)$ \\
Outcome $\neq$ & & $5(1.7)$ \\
Recovered & $450(71.7)$ & $97(33.6)$ \\
Recovered with sequelae & $4(0.6)$ & $6(2.1)$ \\
Ongoing & $165(26.3)$ & $289(100.0)$ \\
Unknown & $9(1.4)$ & \\
Total number of events & $628(100.0)$ & \\
\hline
\end{tabular}

${ }^{*}$ Adverse events occurring in at least $10 \%$ of all patients.

†Percentages of adverse event frequencies are calculated as proportions of all patients in specified treatment group $(=\mathrm{N})$.

$\ddagger$ Percentages of adverse event intensities and outcomes are based on total number of events in specified treatment group.

$\%$, percentages; $n$, number of events in specified category; $N$, number of patients in specified treatment group.

findings of an earlier randomised, double blind, crossover study which compared the same CE and placebo where the respective proportion was $23.2 \%$. $^{25}$

Not surprisingly, the overall rate of AEs was higher in the CE group than in the placebo group with the highest rate at the end of the dose escalation phase. A marked continuous decrease in $\mathrm{AE}$ rates was observed over the remainder of the study (16.8\%). A similar trend was observed in the placebo group, although the changes in $\mathrm{AE}$ rates over the course of the study were not as pronounced. Thus the greatest difference between AE rates was observed during the titration phase and can reasonably be attributed to the fast dose escalation. In this study, fast dose escalation to the individual maximum tolerated dose was distinctly different from the CAMS study and was chosen deliberately to ensure that none of the potential efficacy of $\mathrm{CE}$ was missed, since an absolute maximum dose cannot be specified. Thus a higher rate of $\mathrm{AEs}$ and, in consequence, $\mathrm{AE}$ related withdrawals, had to be accepted.

Table 8 Frequency of adverse events over the study

\begin{tabular}{llll}
\hline & $\begin{array}{l}\text { Cannabis } \\
\text { extract } \\
(\mathbf{N}=\mathbf{1 4 3}) \\
\mathbf{n}(\%)\end{array}$ & $\begin{array}{l}\text { Placebo } \\
(\mathbf{N = 1 3 4 )} \\
\mathbf{n}(\%)\end{array}$ & $\begin{array}{l}\text { Cannabis } \\
\text { extract compared } \\
\text { with placebo } \\
\mathbf{p} \text { Value* }\end{array}$ \\
\hline Visits 2 and 3 & $108(75.5)$ & $51(38.1)$ & $<0.001$ \\
Visits 3 and 4 & $66(46.2)$ & $42(31.3)$ & 0.012 \\
Visits 4 and 5 & $49(34.3)$ & $39(29.1)$ & 0.357 \\
Visits 5 and 6 & $43(30.1)$ & $42(31.3)$ & 0.819 \\
\hline
\end{tabular}

*Cochran-Mantel-Haenszel- $\chi^{2}$ test ( $\alpha=0.05$, two sided).

$\mathrm{AE}$, adverse event; \%, percentage (based on $N$ ); $n$, number of patients with events in specified category; N, number of patients in specified treatment group.
A second point regarding tolerability of $\mathrm{CE}$ is that the fast dose escalation and strict clinical trial titration regimen (only one titration was allowed) in this study does not reflect normal clinical routine in which dose titration can be performed more slowly and where more up and down titration usually occurs.

As expected, CNS symptoms occurred at a higher rate under the psychoactive CE compared with placebo $(24.5 \%$ vs $7.5 \%)$. Most CNS AEs were mild, the most common being disorientation and confusion.

Muscle spasms, musculoskeletal stiffness and pain-the main outcomes of this trial-were reported as AEs at low frequencies, and with only small differences between treatment groups. Three SAEs (urinary tract infection, head injury and interstitial lung disease) were considered treatment related by the investigator.

Although patients taking $\beta$-interferon were excluded from this short term study, this was in order to prevent any confounding of spasticity induced by interferon administration. There is no reason to believe that any treatment effect would not be seen in patients taking $\beta$-interferon, or any other immunomodulatory drug.

The CAMS study is still the largest study to have assessed the effect of a standardised CE on MS symptoms. The present MUSEC study results confirmed the positive effects seen in CAMS, and were also similar to the findings of two other studies that showed a significant reduction on an 11 point numerical spasticity rating scale in patients treated with an oromucosal cannabinoid. ${ }^{1026}$ In assessing the context of these results, it must be acknowledged that the level of evidence for many approved drugs to combat symptoms is weak. Clinical experience provides evidence that baclofen may cause more weakness in already weak patients, and the effect of tizanidine is often unsatisfactory. A recent Cochrane review of antispasticity agents for MS concluded that the paucity of evidence meant that no prescribing recommendations can be made, and that better outcome measures need to be developed. ${ }^{27}$ This may explain why $40 \%$ of participants in this study did not receive any other antispasticity medication. In order to circumvent high non-responder rates, an enriched study design has recently been used to evaluate an oromucosal cannabinoid, at the cost of provoking a very high placebo response rate. ${ }^{10}$ In the present study, we were able to demonstrate significant efficacy without resorting to such measures. Clearly, the difficulty in identifying patient responders within study groups may dilute apparent treatment effects and there is a considerable need to develop methodology in this area.

Our findings suggest that standardised CE can be clinically useful in treating the highly complex phenomenon of spasticity in $\mathrm{MS}$, and that an 11 point numerical rating change scale is a useful instrument to measure the treatment effect of relief from muscle stiffness. Effective pain relief is also achieved by $\mathrm{CE}$, especially in patients with a high baseline pain score.

Acknowledgements We thank all patients who took part in the study, and would also like to express our gratitude to the members of the IDMC.

Contributors JPZ was the chief investigator, and led the design, conduct and interpretation of the study. JCH and AS conducted several analyses and reviewed the paper in preparation. DB and PGM were the leading investigators in the study and reviewed the manuscript prior to publication.

Funding Funded by the Society for Clinical Research, Berlin, Germany, and Weleda AG, Arlesheim, Switzerland.

Competing interests JPZ has received consultancy fees from IKF and Bayer-Schering. He has received funding from the MRC and NIHR EME to conduct studies using cannabinoids. He is a named inventor in two patents regarding cannabinoid use in multiple sclerosis. JCH has received honoraria, consulting fees or, 
support for conferences from, or contributions towards research from Acorda, Biogen Idec, Merck Serono, Bayer Schering, Teva and MAPI industries.

Ethics approval Ethics approval was provided by Scotland A Research Ethics Committee.

Provenance and peer review Not commissioned; externally peer reviewed.

\section{REFERENCES}

1. Paty DW, Ebers GC. Multiple sclerosis. Philadelphia, PA: FA Davis, 1998

2. Eisenberg DM, Davis RB, Ettner SL, et al. Trends in alternative medicine use in the United States, 1990-1997; results of a follow-up national survey. JAMA 1998;280:1569-75.

3. Schwartz CE, Laitin E, Brotman $\mathrm{S}$, et al. Utilization of unconventional treatments by persons with MS: is it alternative or complementary? Neurology 1999;52:626-9.

4. House of Lords Committee on Science and Technology. Cannabis: the Scientific and Medical Evidence, 9th report, 1998. http://www.publications.parliament.uk/pa/ Id199798/Idselect/Idsctech/151/15101.htm (accessed Jan 2012).

5. Zajicek J, Fox P. Sanders H et al. Cannabinoids for treatment of spasticity and other symptoms related to multiple sclerosis (CAMS study): multicentre randomised placebo-controlled trial. Lancet 2003;362:1517-26.

6. Zajicek JP, Sanders HP, Wright DE, et al. Cannabinoids in multiple sclerosis (CAMS) study: safety and efficacy data for 12 months follow up. J Neurol Neurosurg Psychiatry 2005;76:1664-9.

7. Hobart J, Thompson A. Measurement of neurological outcomes. In: Asbury AK McKhann GM, McDonald WI, et al, eds. Diseases of the nervous system: clinical neuroscience and therapeutic principles. 3rd edn. Cambridge, UK. Cambridge University Press, 2002:105-17.

8. Fleuren JF, Voerman GE, Erren-Wolters CV, et al. Stop using the Ashworth Scale for the assessment of spasticity. J Neurol Neurosurg Psychiatry 2010;81:46-52.

9. CPMP/EWP/252/03 Rev. 1. Guideline of clinical investigation of medicinal products intended for the treatment of neuropathic pain. EMEA, 2007. http://www.ema. europa.eu/ema/index.jsp?curl=pages/regulation/general/general content 000425. jsp\&murl=menus/regulations/regulations.jsp\&mid=WC0b01ac0580034cf5 gjsenabled=true http://www.ema.europa.eu/docs/en GB/document library/ Scientific guideline/2009/09/WC500003478.pdf (accessed Jan 2012).

10. Novotna A, Mares J, Ratcliffe S, et al. A randomized double blind placebocontrolled, parallel group, enriched design study of nabiximols (Sativex®) as add-on therapy in subjects with refractory spasticity caused by multiple sclerosis. Eur J Neurol 2011;18:1122-31.

11. McDonald WI, Compston A, Edan G, et al. Recommended diagnostic criteria for multiple sclerosis: guidelines from the International Panel on the diagnosis of multiple sclerosis. Ann Neurol 2001;50:121-7.

12. Hobart JC, Riazi A, Thompson AJ, et al. Getting the measure of spasticity in multiple sclerosis: the Multiple Sclerosis Spasticity Scale (MSSS-88). Brain 2006;129:224-34.

13. Hobart JC, Lamping DL, Fitzpatrick $\mathrm{R}$, et al. The Multiple Sclerosis Impact Scale (MSIS-29): a new patient-based outcome measure. Brain 2001;124:962-73.

14. Hobart JC, Riazi A, Lamping DL, et al. Measuring the impact of MS on walking ability. The 12-item MS-Walking scale (MSWS-12). Neurology 2003;60:31-6.

15. Kurtzke JF. Rating neurologic impairment in multiple sclerosis: an Expanded Disability Status Scale (EDSS). Neurology 1983;33:1444-52.

16. Casagrande JT, Pike MC, Smith PG. An approximate formula for calculating sample sizes for comparing two binomial distributions. Biometrics 1978;34:483-6.
17. ADDPLAN. Adaptive designs - plans and analyses, release 4; software documentation. Cologne: Addplan GmbH, 2007. http://www.addplan.com laccessed Jan 2012).

18. Wassmer G. Data-driven analysis strategies for proportion studies in adaptive group sequential test designs. J Biopharm Stat 2003;13:585-603.

19. O'Brien PC, Fleming TR. A multiple testing procedure for clinical trials. Biometrics 1979;35:549-56

20. SAS/STAT Version 8.02 of the SAS system for Windows. Cary NC, USA: SAS Institute Inc., 1997

21. Rasch G. Probabilistic models for some intelligence and attainment tests. Copenhagen: Danish Institute for Education Research, 1960.

22. Andrich D. A rating formulation for ordered response categories. Psychometrika 1978;43:561-73

23. Hobart J, Cano S, Zajicek J, et al. Rating scales as outcome measures for clinical trials in neurology: problems, solutions, and recommendations. Lancet Neurol 2007; 6:1094-105.

24. Hobart J, Cano S. Improving the evaluation of therapeutic intervention in MS: the role of new psychometric methods. Health Technol Assess 2009:13:iii, ix-x,1-177.

25. Vaney C, Heinzel-Gutenbrunner M, Jobin P, et al. Efficacy, safety and tolerability of an orally administered cannabis extract in the treatment of spasticity in patients with multiple sclerosis: a randomised, double-blind, placebo-controlled, crossover study. Mult Scler 2004;10:417-24.

26. Collin C, Davies P, Mutiboko IK, et al. Randomized controlled trial of cannabisbased medicine in spasticity caused by multiple sclerosis. Eur $\mathrm{J}$ Neurol 2007:14:290-6.

27. Shakespeare DT, Boggild M, Young C. Anti-spasticity agents for multiple sclerosis (Cochrane Review). Cochrane Database Syst Rev 2003;4:CD001332.

\section{APPENDIX}

\section{MUSEC Research Group}

The following were lead investigators at each site, as part of the MUSEC Research Group, and contributed patients to the MUSEC study: Dr D Barnes (Atkinson Morley's Hospital, London): Professor D Bates (Royal Victoria Infirmary, Newcastle); Dr P Carriga (Hull Royal Infirmary); Dr D Chan (Royal Sussex County Hospital, Brighton) Dr CS Constantinescu (University Hospital, Nottingham): Dr E Fathers (Taunton and Somerset Hospital); Dr CP Hawkins (North Staffordshire Royal Infirmary); Dr SJL Howell (Royal Hallamshire Hospital, Sheffield); Dr A labal (Community Rehabilitation and Respite Unit, Barnsley); Dr 0 Lily (Leeds General Infirmary); Dr PG Mattison (Ayrshire Central Hospital); Dr M Mavra (Southend Hospital, Westcliff on Sea): Dr P McKee (James Cook University Hospital, Middlesbrough); Dr RG Miller (Colchester General Hospital); Dr CP O'Leary (Southern General Hospital, Glasgow); Dr MF Phillips (Derby City General Hospital); Dr C Rickards (Morriston Hospital, Swansea); Dr N Scolding (Frenchay Hospital, Bristol); Dr SA Shields (Norfolk and Norwich University Hospital): Dr E Silber (Kings College Hospital, London); Dr BA Summers (Staffordshire General Hospital, Stafford); Professor JP Zajicek (Derriford Hospital, Plymouth).

\section{Steering committee}

Martin Schnelle, Marcus Reif, John Zajicek, Michael Werner and Rainier Dierdorf.

Data monitoring and ethics committee

Chris Polman (chair), Alan Thompson, Gernot Wassmer. 